Rabaska

Revue d'ethnologie de l'Amérique française

\title{
Centre d'études acadiennes Anselme-Chiasson (Université de Moncton)
}

\section{Robert Richard}

Volume 12, 2014

URI : https://id.erudit.org/iderudit/1026828ar

DOI : https://doi.org/10.7202/1026828ar

Aller au sommaire du numéro

Éditeur(s)

Société québécoise d'ethnologie

ISSN

1703-7433 (imprimé)

1916-7350 (numérique)

Découvrir la revue

Citer ce document

Richard, R. (2014). Centre d'études acadiennes Anselme-Chiasson (Université de Moncton). Rabaska, 12, 332-333. https://doi.org/10.7202/1026828ar d'utilisation que vous pouvez consulter en ligne.

https://apropos.erudit.org/fr/usagers/politique-dutilisation/ 


\section{Rapports des institutions}

\section{ACADIE}

\section{Centre d'études acadiennes Anselme-Chiasson}

Université de Moncton

Moncton (Nouveau-Brunswick)

E1A 3E9
Téléphone : (506) 858-4085

Télécopieur : (506) 858-4530

Courriel : robert.richard@umoncton.ca

Toile : www.umoncton.ca/umcm-CÉACC

\section{Laboratoire de conservation et traitement}

Parmi plusieurs autres activités qui sont prévues dans le plan de mise en production du nouveau système de gestion de l'information (Progiciel Ultima) du Centre d'études acadiennes Anselme-Chiasson, Robert Richard, de concert avec l'archiviste Carl F. Eisan, le technicien François LeBlanc du CÉACC, y compris un informaticien très attentionné, ont concerté leurs efforts pour le transfert (relocalisé) et la conversion (WAV à MP3) de l'intégralité des fichiers audionumériques (4.2 To) des archives de folklore du CÉACC. Conséquemment, un premier lot de 9000 enregistrements sonores numériques (MP3) devra bientôt être importé dans ce système.

\section{Acquisitions}

Le professeur titulaire associé de l'Université de Sherbrooke François Corpataux a déposé au CÉACC une partie des enregistrements de sa collection intitulée Le chant des enfants du monde (Franciscorpataux.com), en particulier ceux de son collectage audio et audiovisuel effectué dans diverses localités acadiennes des provinces maritimes. Dans un élan similaire, la donatrice Valérie DuBocquet de Paquetville a déposé près d'une demi-douzaine d'enregistrements sonores, notamment des contes créés et racontés par son frère, le regretté conteur Alfred Léger (1936-2013). Quant à Claudette Barrieau-Richard, elle y est allée d'un dépôt de huit photos d'époque, dont quatre sont des coureurs de la Mi-Carême de la région de Bédec, au sud-est du Nouveau-Brunswick. Pour sa part, Robert Richard enregistrera entre 2014 et 2015 des images audiovisuelles du conservateur Bernard LeBlanc, dans le but de capter en format binaire une infime partie de son savoir sur une sélection d'objets de la collection du Musée acadien de l’Université de Moncton (MAUM).

\section{Consultations, communications et collaborations}

À même les locaux du CÉACC au semestre d'hiver 2014, Robert Richard a répondu aux demandes et a facilité l'accès aux archives du professeur d'histoire comparée 
des religions Denise Lamontagne de l'Université de Moncton et de ses étudiantes inscrites au séminaire sur les croyances populaires en Acadie. L'archiviste en ethnologie acadienne a fait de même avec les demandes de reproduction et de consultation d'étudiantes et d'étudiants de la même université, particulièrement celles de la doctorante Carmen d'Entremont sur la mystification et de Marc-André Robichaud, comédien au Pays de la Sagouine en saison estivale. Il a également répondu à celles reçues de quelques-uns des conférenciers du colloque sur la musique traditionnelle acadienne et celtique qui s'est tenu en octobre dernier à la Cape Breton University. Bénéficiant d'une bourse de séjour de recherche, appuyé entre autres par le CÉACC, le doctorant Nathan J. Rabalais de l'Université Tulane (Nouvelle-Orléans) dépouille en ce moment les collections de contes du CéACC. Son sujet de thèse porte sur le conte de « folklore louisianais et ses rapports aux traditions orales acadiennes, françaises et africaines (N. Rabalais) ». Robert Richard en a fait autant avec la conservatrice du Maum, Jeanne-Mance Cormier, dans le développement du contenu de ses collections et de ses ateliers pédagogiques. Ailleurs, le groupe de musique folklorique du Québec Le Bruit court dans la ville (Lebruitcourtdanslaville.com) a puisé dans le collectage (1977) de Pauline Banville et Adèla Collette deux reels à bouche du répertoire d'Isaïe LeBlanc (Coal Branch, N.-B.), utilisés pour la composition d'une des douze pièces du second album titré Les vents qui ventent. Lors de la $5^{\mathrm{e}}$ édition du festival Parlures d'icitte, qui s'est déroulé dans la vallée de Memramcook en octobre 2013, Robert Richard s'est joint à Luc LeBlanc, parrain du festival et interprète du personnage Citrouille au Pays de la Sagouine, pour une table ronde qui avait pour titre «Osez conter ». De plus, il a présenté une communication à la table ronde, intitulée « La remise en valeur du savoir des conteurs traditionnels acadiens », en compagnie de Ronald Labelle et Jean-Pierre Pichette, à l'occasion du colloque L'Acadie dans tous ses défis (Congrès mondial acadien 2014). Enfin, Robert Richard a accepté de collaborer avec la conservatrice invitée Deborah Robichaud et la conservatrice du MAUm au développement de l'exposition temporaire sur les traditions et les coutumes entourant la mort et le deuil en Acadie. Le vernissage est prévu à l'automne 2015.

ROBERT RICHARD 